\title{
Corrosion Behavior of Nickel Base Heat Resisting Alloys for Nuclear Steelmaking System in High-temperature Steam*
}

\author{
By Fujio ABE, ** Hiroshi ARAKI,** Heitaro YOSHIDA*** and \\ Masatoshi OKADA**
}

\begin{abstract}
Synopsis
The corrosion behavior of nickel base heat resisting alloys is investigated in steam at $800^{\circ} \mathrm{C}$ and $40 \mathrm{~atm}$, simulating the superheated steam of the nuclear steelmaking system. The alloys tested are five new alloys developed for the nuclear steelmaking system and one commercial alloy Inconel 617.

A protective surface oxide scale, consisting of $\mathrm{Cr}_{2} \mathrm{O}_{3}$ mainly and of $\mathrm{MnCr}_{2} \mathrm{O}_{4}$, forms on the alloys except Inconel 617. Internal oxides, consisting of $\mathrm{Al}$ and $\mathrm{Ti}$ oxides, also form in the alloys containing $\mathrm{Al}$. For Inconel 617, nodular oxides, consisting of $\mathrm{NiO}$ in the outer region and $\mathrm{Cr}$ internal oxides in the inner region, form in addition to $\mathrm{Cr}_{2} \mathrm{O}_{3}$ and $\mathrm{MnCr}_{2} \mathrm{O}_{4}$ after $1000 \mathrm{~h}$. No decarburization occurs in each alloy.

The effect of alloy compositions on the corrosion behavior is discussed. The rate of $\mathrm{Cr}$ depletion resulting from the formation of $\mathrm{Cr}_{2} \mathrm{O}_{3}$-rich scale is found to be influenced by the presence of $\mathrm{MnCr}_{2} \mathrm{O}_{4}$ layer outside the $\mathrm{Cr}_{2} \mathrm{O}_{3}$ scale, and is described by a parabolic rate law for the alloys with thin $\mathrm{MnCr}_{2} \mathrm{O}_{4}$ layer and by a cubic rate law for the alloys with thick $\mathrm{MnCr}_{2} \mathrm{O}_{4}$ layer. $\mathrm{Al}$ and $\mathrm{Ti}$, which are reactive more than $\mathrm{Cr}$, are found to improve a resistance to spalling of the $\mathrm{Cr}_{2} \mathrm{O}_{3}$-rich scale, through a key-on effect by the internal oxides and by the enrichment of $\mathrm{Ti}$ oxides at the $\mathrm{Cr}_{2} \mathrm{O}_{3}$ scale/alloy interface.
\end{abstract}

\section{Introduction}

The nuclear steelmaking system utilizes a nuclear energy of a high temperature gas-cooled reactor (HTGR) as a process heat for direct steelmaking of iron ore, and this has been developed as a national project in Japan. ${ }^{1,2)}$ In the system, a hydrogen base reducing gas mixture, $\mathrm{H}_{2}-15 \% \mathrm{CO}-5 \% \mathrm{CO}_{2}$, is produced by a thermal decomposition of naphtha with steam and is intended to be used for direct steelmaking. Heat from HTGR is used for the system, through helium gas. Steam superheater elements of the system consist of thin-walled tubes of $25 \mathrm{~mm}$ diameter and $5 \mathrm{~mm}$ wall thickness. The tubes are heated on the outside by the helium gas at about $850{ }^{\circ} \mathrm{C}$. The pressure of the steam is about $45 \mathrm{~atm}$. Temperature of the superheated steam in the system is quite high in comparison with those in typical electric power plants which are below $650^{\circ} \mathrm{C}$. Therefore, severe environmental conditions will be encountered in the steam superheater tubings of the nuclear steelmaking system. This requires good resistance to corrosion in steam at high temperatures, especially $800 \sim 900{ }^{\circ} \mathrm{C}$.

Scale plugging of stainless steel superheater tubes is one of the corrosion problems of metallic materials used in high-temperature steam. ${ }^{3)}$ Owing to a higher oxidation rate of stainless steels in high-temperature steam, a large amount of scale of surface oxide spalls and accumulates at a certain part of superheater tubes. This causes the plugging. This problem has been experienced by a considerable number of power stations. Therefore, a good resistance to spalling of the oxide scale is another requirement for the steam superheater tubings.

The purpose of the present research is to investigate the corrosion behavior of nickel base heat resisting alloys. Five alloys, NSG-1, $\left.\left.{ }^{4} \mathrm{SZ},{ }^{5}\right) \mathrm{KSN},{ }^{6}\right) 113 \mathrm{M}^{7}$ and $\mathrm{R} 4286,{ }^{8)}$ newly developed for the metallic components of the nuclear steelmaking system and one commercial Inconel 617 are examined in high-temperature steam, simulating the superheated steam of the nuclear steelmaking system. The alloys are corroded in steam at $800{ }^{\circ} \mathrm{C}$ and $40 \mathrm{~atm}$ pressure for 300 , 1000 and $3000 \mathrm{~h}$. Weight gain, depth of Cr depleted zone, depth of internal oxidation and change in carbon concentration are measured in order to evaluate the amount of corrosion of the alloys in the steam. The effect of the alloy compositions on the corrosion behavior is discussed.

The present research has been carried out as a part of the project "The Research and Development of Direct Steelmaking Technology Using Reducing Gas," which is one of the National Research and Development Programs by the Agency of Industrial Science and Technology, the Ministry of International Trade and Industry in Japan. For the alloys newly developed for the nuclear steelmaking system, the results on the high-temperature properties of the alloys in various environments simulating the system were already reported, such as creep rupture properties in impure helium ${ }^{9-12)}$ and reducing gas, ${ }^{10-12)}$ fatigue properties in impure helium ${ }^{13)}$ and hydrogen permeation in reducing gas. ${ }^{14)}$

\section{Experimental Method}

The chemical compositions of the alloys examined are given in Table 1. The solution annealed alloys were supplied in the form of sheets of $100 \times 20 \times 2 \mathrm{~mm}$; NSG-1 from Nippon Steel Corp., SZ from Sumitomo Metal Industries, Ltd., KSN from Kobe Steel, Ltd., $113 \mathrm{M}$ and R4286 from Hitachi Metals Ltd., and Inconel 617 from Ishikawajima-Harima Heavy Industries Co., Ltd. Sheet specimens of $20 \times 10 \times 2 \mathrm{~mm}$ with two holes of $1 \mathrm{~mm}$ in diameter at the upper and lower parts, were cut from the materials by a watercooled fine cutter, ground on emery papers, rinsed in acetone and then supplied to the corrosion test.

* Presented to the 101st ISIJ Meeting, April 1981, S594, at The University ó Tokyo in Tokyo. Manuscript received on October 29, 1984; accepted in the final form on December 7, 1984. (C) 1985 ISIJ

** Tsukuba Laboratories, National Research Institute for Metals, Sakuramura, Niihari-gun, Ibaraki 305.

*** National Research Institute for Metals, Nakameguro, Meguro-ku, Tokyo 153. 
Table 1. Chemical compositions of the alloys tested. (wt\%)

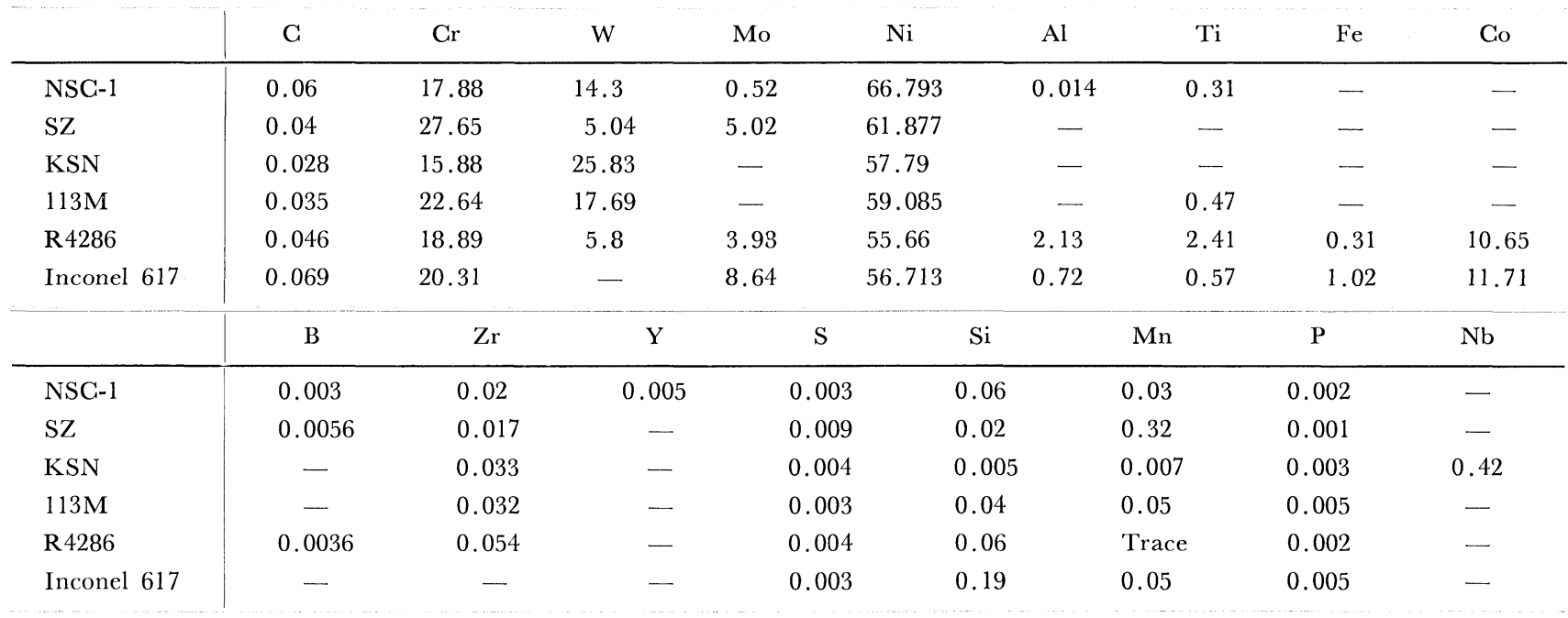

The two holes were used to suspend the specimens from the specimen holder.

The corrosion test was carried out in a Hastelloy$\mathrm{X}$ autoclave shown in Fig. 1. Specimens were corroded for 300,1000 and $3000 \mathrm{~h}$ in steam at $800{ }^{\circ} \mathrm{C}$ and $40 \mathrm{~atm}$. The flow rate of the steam was $3 \mathrm{l} / \mathrm{h}$. The purified water with an electric conductivity of $4 \times 10^{-7}(\Omega-\mathrm{cm})^{-1}$ and a dissolved oxygen concentration of $0.1 \mathrm{ppm}$ was pumped to a preheater at a flow rate of $0.42 \mathrm{ml} / \mathrm{min}$ corresponding to $3 l / \mathrm{h}$ of steam at $800{ }^{\circ} \mathrm{C}$ and $40 \mathrm{~atm}$. Steam was generated and heated up to $800{ }^{\circ} \mathrm{C}$ in the preheater before entering the autoclave. The details of the experimental procedure are described elsewhere. ${ }^{15)}$

Specimens were weighed by a microbalance, having a sensitivity of $1 \mu \mathrm{g}$, before and after the corrosion test. The surface oxide constituents were identified by Xray diffraction using filtered $\mathrm{Cu} \mathrm{K} \alpha \quad(\lambda=1.5405 \AA)$ radiation at $30 \mathrm{kV}$ and $20 \mathrm{~mA}$. The diffraction studies were carried out on the as-corroded specimens at room temperature. The diffraction patterns were compared with ASTM (American Society for Testing Materials) cards. The surface and the polished sections of the specimens were also examined by a scanning electron microscope and an electron probe microanalyzer. Carbon content of the specimens was measured by a LEGO IR-12 carbon analyzer.

\section{Experimental Results}

\section{Weight Gain}

Figure 2 shows weight gain curves of the alloys in log-log scale. As will be described later, no change in carbon content was found in the present experimental conditions in the alloys, indicating that weight gain is due to oxidation during exposure to the steam. The weight gain curves of the alloys SZ and KSN show a distinct minimum at $1000 \mathrm{~h}$. This is caused by the spalling of surface oxide scale as shown in Photo. 1. The portions where the spalling has occurred show a metallic luster and a bared alloy surface, suggesting that the spalling occurred during

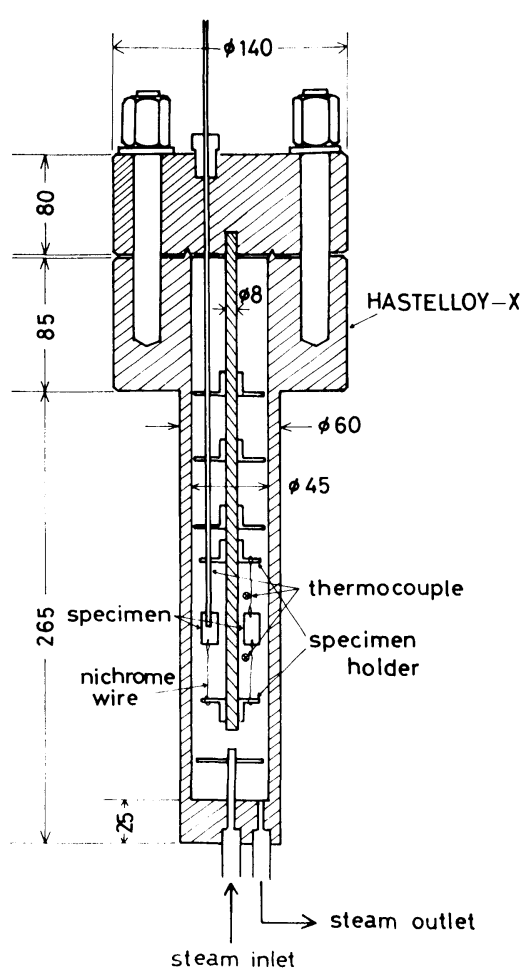

Fig. 1. Autoclave for corrosion test in steam. (All dimensions are in millimeters.)

cooling of the specimens after the corrosion test. The spalling of surface oxide scale on SZ and KSN was also found to occur after the $3000 \mathrm{~h}$ test. On the other hand, no spalling was observed on the alloys except SZ and KSN.

When the weight gain $\Delta W$ is expressed by $\Delta W=$ $k t^{n}$, where $k$ is the rate constant and $t$ the exposure time, time exponent $n$ is found to be about $1 / 2$ for $\mathrm{R} 4286$, corresponding to a parabolic rate law, and about $1 / 3$ for NSC-1 and $113 \mathrm{M}$. The time exponent for Inconel 617 is not given by a single value, because the corrosion behavior changes after $1000 \mathrm{~h}$ as will be described later. The value of $n$ for Inconel 617 is greater than $1 / 2$ after $1000 \mathrm{~h}$. The evaluation of 


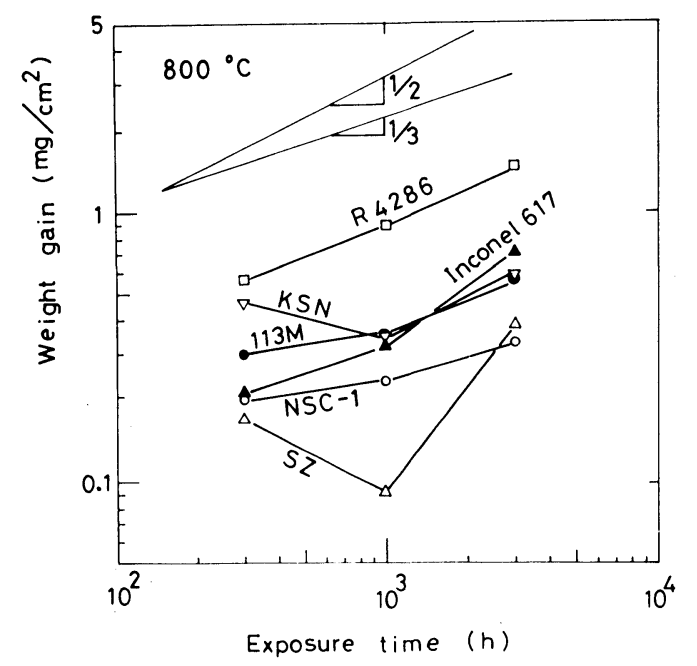

Fig. 2. Weight gain curves of the alloys in steam at $800^{\circ} \mathrm{C}$ and $40 \mathrm{~atm}$. Also shown are reference lines with slopes of $1 / 2$ and $1 / 3$, corresponding to parabolic and cubic rate laws, respectively.

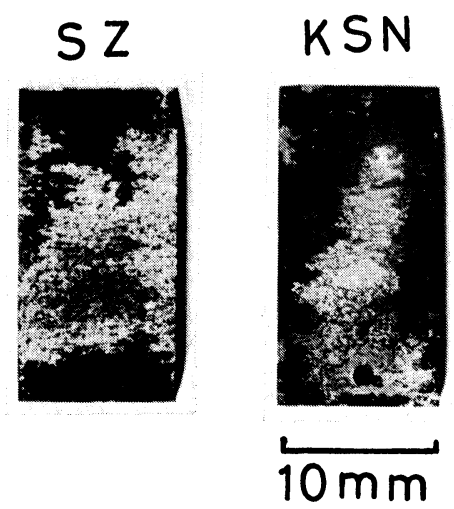

Photo. 1. Specimen appearance of the alloys SZ and KSN corroded for $1000 \mathrm{~h}$ in steam at $800^{\circ} \mathrm{C}$ and $40 \mathrm{~atm}$, showing a spalling of the surface oxides.

$n$ for $\mathrm{SZ}$ and $\mathrm{KSN}$ is not made. Because of the spalling of surface oxide scale, the weight gain curves and $n$ values of $\mathrm{SZ}$ and KSN are not available. Depth of $\mathrm{Cr}$ depleted zone is not affected by the spalling of surface oxide scale during cooling of the specimens after the corrosion test, and this will be described later.

\section{Identification of Surface Oxides}

Figure 3 shows X-ray diffraction patterns of the surface oxides on the alloys corroded for $3000 \mathrm{~h}$. Surface oxides on NSG-1, SZ, KSN and $113 \mathrm{M}$ are identified as $\mathrm{Cr}_{2} \mathrm{O}_{3}$ and $\mathrm{MnCr}_{2} \mathrm{O}_{4}$, which are also typical for the alloys corroded for 300 and $1000 \mathrm{~h}$. The diffraction peaks from tungsten, which are observed on only KSN and $113 \mathrm{M}$, are due to $\alpha-W$ (tungsten rich bcc phase) ${ }^{16,17)}$ precipitates and not due to the corrosion product. In addition to $\mathrm{Cr}_{2} \mathrm{O}_{3}$ and $\mathrm{MnCr}_{2} \mathrm{O}_{4}, \mathrm{TiO}_{2}$ is also formed on $\mathrm{R} 4286$ and $\mathrm{NiO}$ on Inconel 617. Formation of $\mathrm{NiO}$ is observed beyond $1000 \mathrm{~h}$, suggesting the change in the corrosion behavior beyond $1000 \mathrm{~h}$.

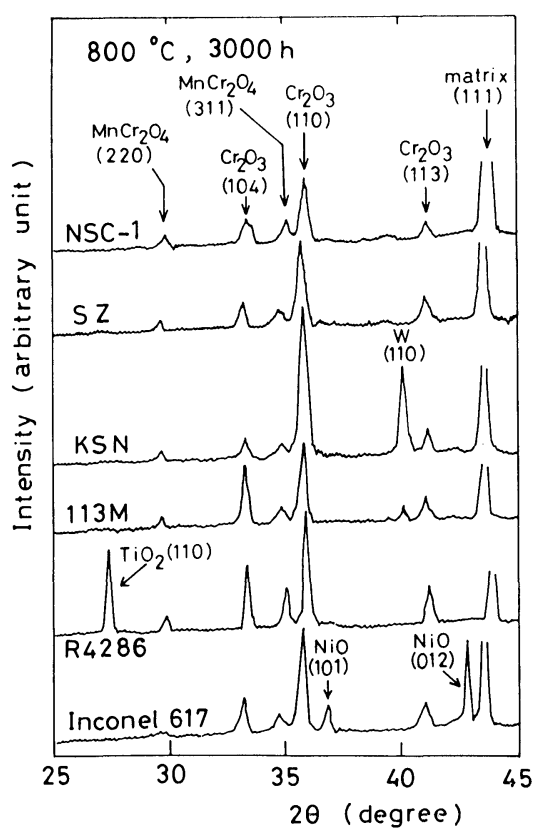

Fig. 3. X-ray diffraction patterns of the alloys corroded for $3000 \mathrm{~h}$ in steam at $800^{\circ} \mathrm{C}$ and $40 \mathrm{~atm}$. CuK $\alpha$ $(\lambda=1.5405 \AA) 30 \mathrm{kV}-20 \mathrm{~mA}$.

\section{Morphology of Oxides}

Photograph 2 shows the morphology of the surface oxides formed on the alloys corroded for $3000 \mathrm{~h}$. The morphology is different considerably among NSC-1, SZ, KSN and 113M in spite of the same kind of oxides, $\mathrm{Cr}_{2} \mathrm{O}_{3}$ and $\mathrm{MnCr}_{2} \mathrm{O}_{4}$, as shown in Fig. 3. The surface oxide scale on NSG-1 and 113M is porous, while that on $\mathrm{SZ}$ and $\mathrm{KSN}$ is composed of densely packed fine oxides. For R4286, a large number of granular oxides of a size about $10 \sim 20 \mu \mathrm{m}$ forms on the oxide scale composed of fine oxides. The morphology of the underlying scale is similar to that on $\mathrm{SZ}$ and $\mathrm{KSN}$ and is composed of fine oxides. As will be described later, the granular oxides are $\mathrm{TiO}_{2}$ and the underlying scale is $\mathrm{Cr}_{2} \mathrm{O}_{3}$ and $\mathrm{MnCr}_{2} \mathrm{O}_{4}$. On Inconel 617 , a large number of nodular oxides is formed. The nodules are composed of oxide grains of a size about $10 \mu \mathrm{m}$ which is considerably larger than those of $\mathrm{Cr}_{2} \mathrm{O}_{3} / \mathrm{MnCr}_{2} \mathrm{O}_{4}$ scale around the nodules.

Photograph 3 shows the cross section through the surface oxide scale of the alloys corroded for $3000 \mathrm{~h}$. Photograph 3 reveals that the scale on SZ and KSN is separated partially from the alloy matrix showing poor adhesion to the matrix. This is closely connected with the spalling of the scale on $\mathrm{SZ}$ and KSN shown in Photo. 1. The scale formed on NSG-1, $113 \mathrm{M}, \mathrm{R} 4286$ and Inconel 617 shows good adhesion. Root-like internal oxides are found in the matrix of R4286 and Inconel 617.

Photograph 4 shows the cross section through the nodular oxide of Inconel 617 corroded for $3000 \mathrm{~h}$. The nodular oxide consists of two regions; an outer and an inner regions. The outer region consists of columnar oxide grains normal to the alloy surface. The inner region is the internal oxide with a con- 


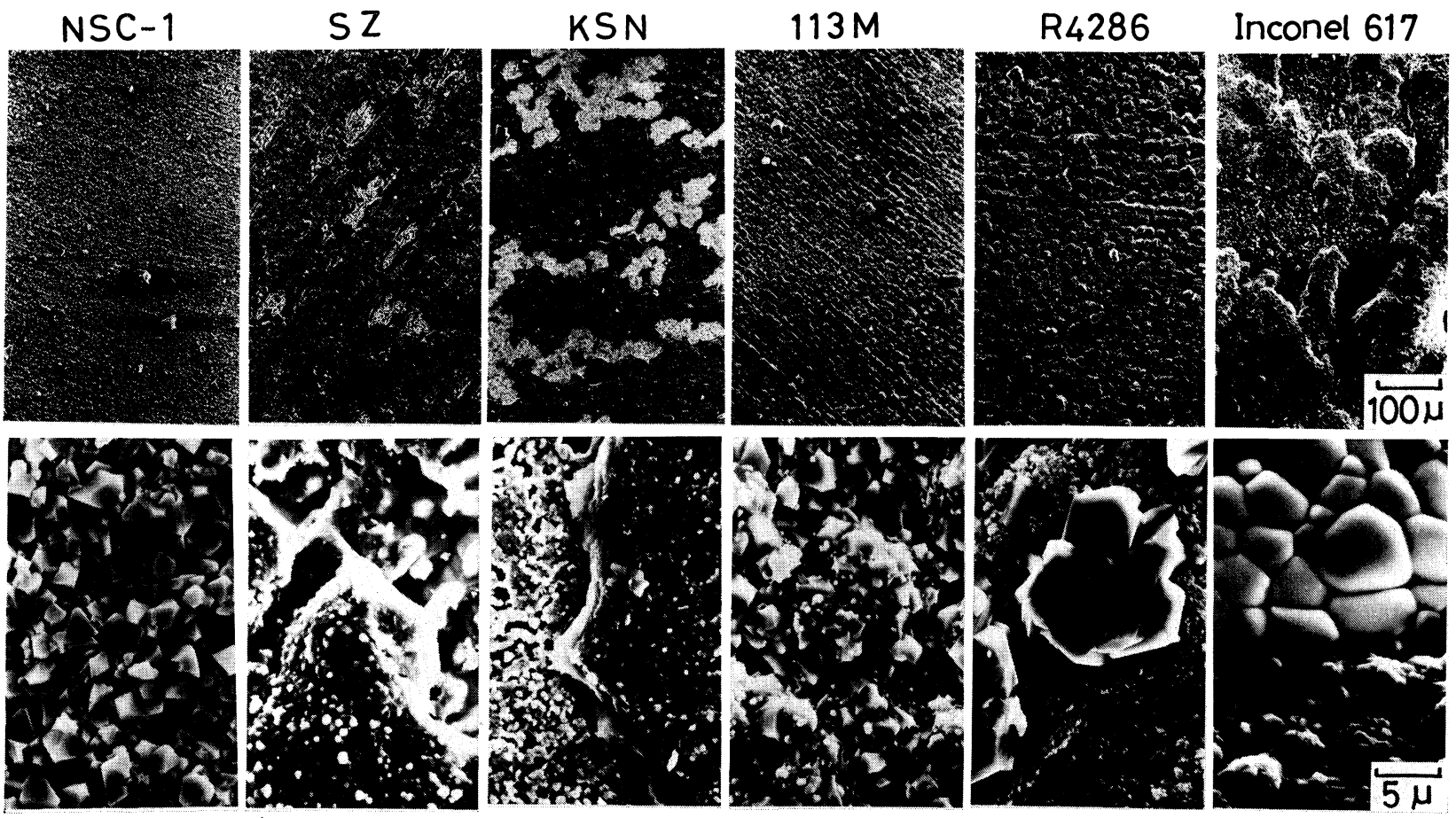

Photo. 2. Scanning electron micrographs of the surface oxides formed on the alloys corroded for $3000 \mathrm{~h}$ in steam at $800{ }^{\circ} \mathrm{C}$ and $40 \mathrm{~atm}$. Micrographs in the lower row are high magnification ones of those in the upper row.
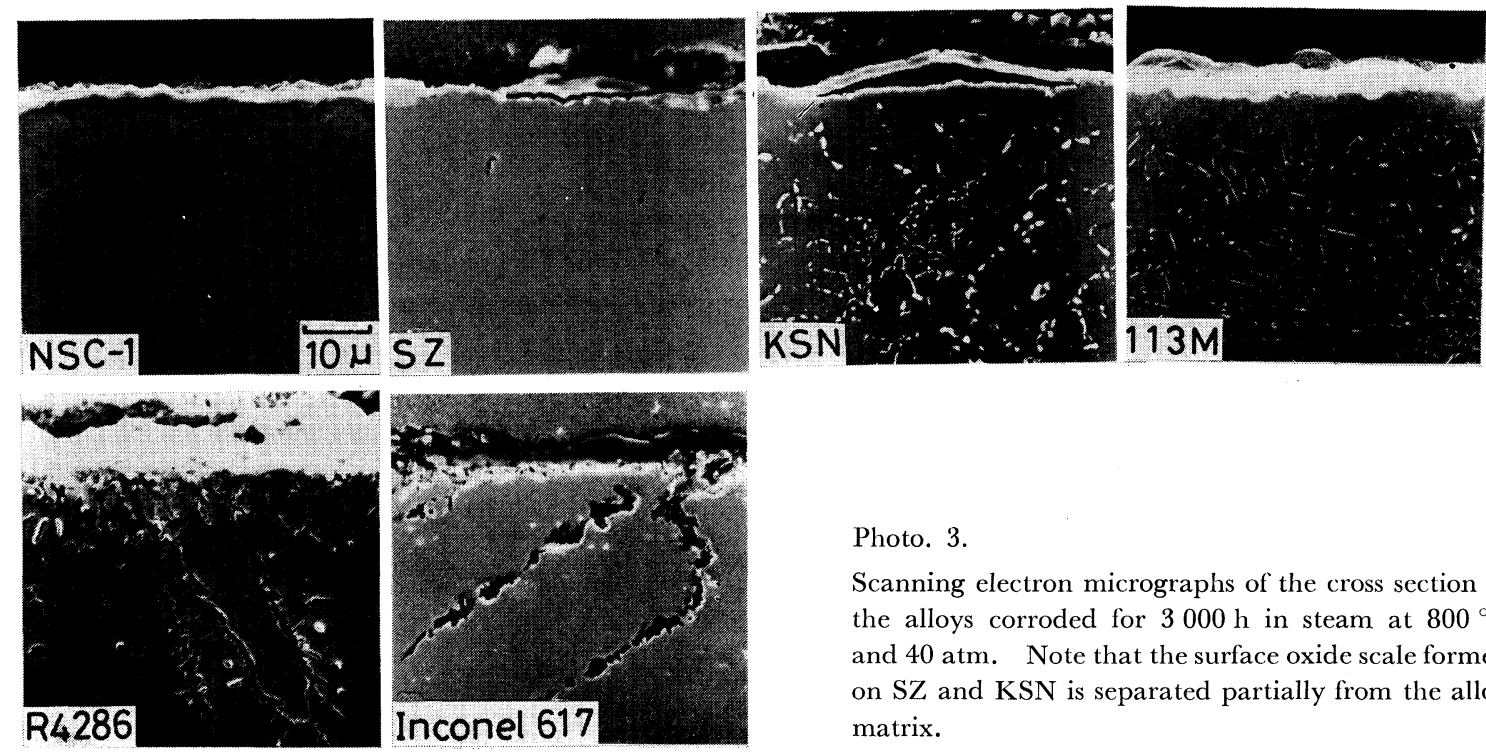

Photo. 3.

Scanning electron micrographs of the cross section of the alloys corroded for $3000 \mathrm{~h}$ in steam at $800^{\circ} \mathrm{C}$ and $40 \mathrm{~atm}$. Note that the surface oxide scale formed on SZ and KSN is separated partially from the alloy matrix.

Photo. 4.

Scanning electron micrograph of the cross section through nodular oxide formed on Inconel 617 corroded for $3000 \mathrm{~h}$ in steam at $800{ }^{\circ} \mathrm{C}$ and $40 \mathrm{~atm}$.

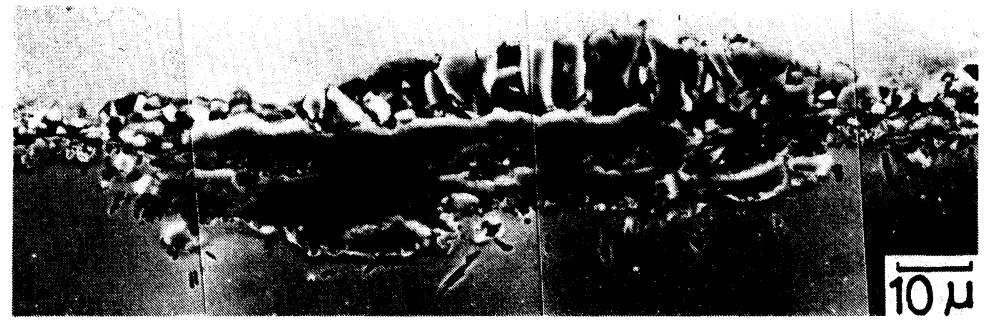

tinuous band-like feature in the alloy matrix. The interface between the two regions coincides closely with the original alloy surface. The nodular oxides show good adhesion similar to the $\mathrm{Cr}_{2} \mathrm{O}_{3}$-rich scale described previously.

\section{Concentration Profiles in Oxides}

Photograph 5 shows characteristic X-ray images of the cross section through the surface oxide scale of the alloys corroded for $3000 \mathrm{~h}$. The scale is rich in $\mathrm{Cr}$ and $\mathrm{Mn}$. The major component of the scale is $\mathrm{Cr}$ oxide for all the alloys, which is identified as $\mathrm{Cr}_{2} \mathrm{O}_{3}$ by X-ray diffraction as shown in Fig. 3. The $\mathrm{Mn}$-rich layer, which is $\mathrm{MnCr}_{2} \mathrm{O}_{4}$, is located outside the $\mathrm{Cr}_{2} \mathrm{O}_{3}$ scale. Thickness of the $\mathrm{MnCr}_{2} \mathrm{O}_{4}$ layer is larger for NSG-1 and SZ compared to the other 


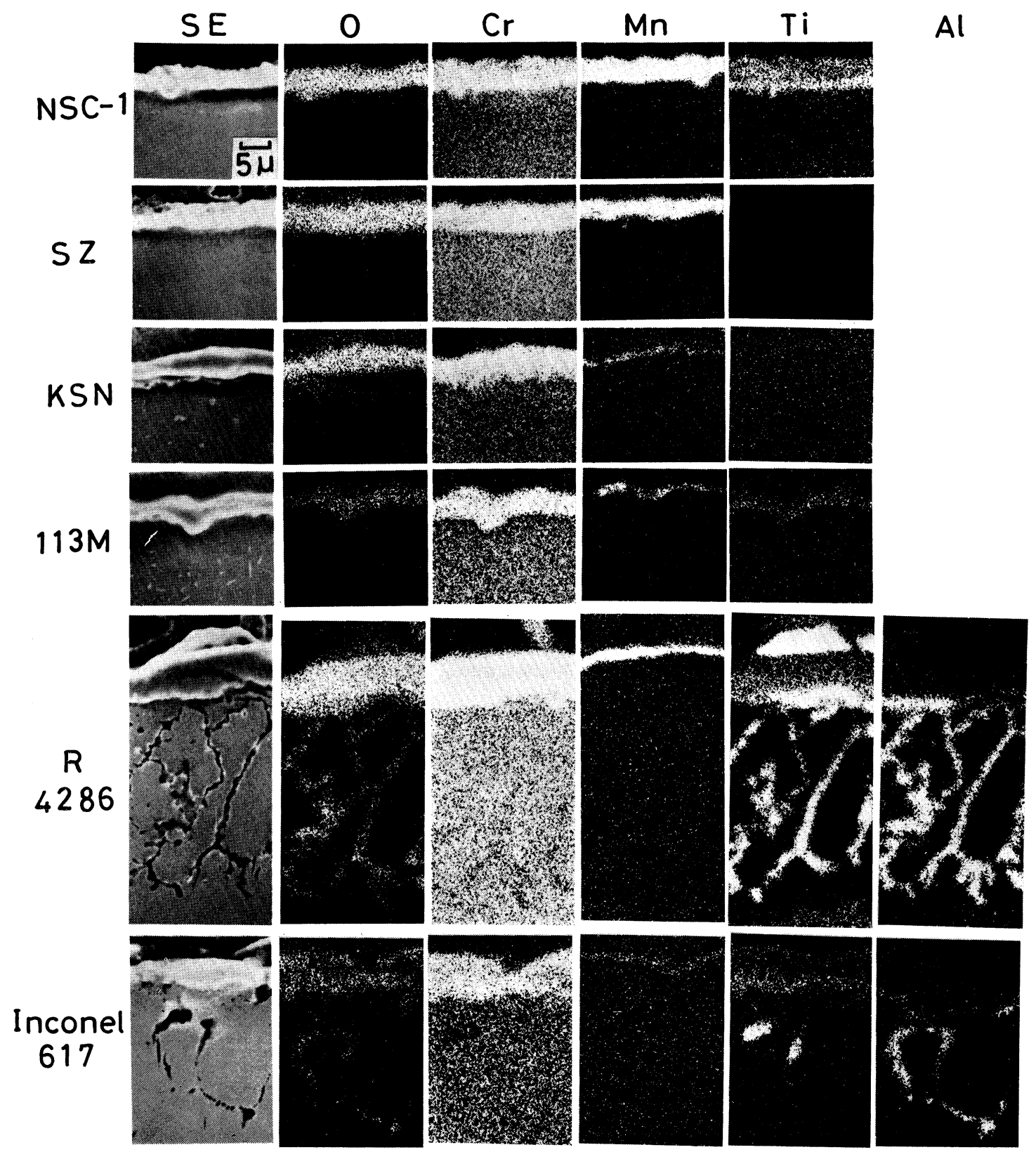

Photo. 5. Characteristic X-ray images of the cross section of the alloys corroded for $3000 \mathrm{~h}$ in steam at $800{ }^{\circ} \mathrm{C}$ and $40 \mathrm{~atm}$. Left-hand sides are secondary electron micrographs.

alloys.

Some quantities of $\mathrm{Ti}$ are contained in the $\mathrm{Cr}_{2} \mathrm{O}_{3}$ scale on NSG-1, 113M and Inconel 617 which have about $0.5 \%$ Ti in the bulk as shown in Table 1 . The enrichment of $\mathrm{Ti}$ is found close to the interface between the $\mathrm{Cr}_{2} \mathrm{O}_{3}$ scale and the alloy matrix. Because no evidence is found for the presence of any Tioxides by X-ray diffraction for the alloys except $\mathrm{R} 4286$, it seems that the $\mathrm{Cr}_{2} \mathrm{O}_{3}$ scale contains some $\mathrm{Ti}$ in solution. For R4286 containing the highest concentration of $\mathrm{Ti}, 2.4 \%$, a large amount of $\mathrm{Ti}$ is detected not only in the $\mathrm{Cr}_{2} \mathrm{O}_{3}$ scale but also in the granular oxides outside the $\mathrm{MnCr}_{2} \mathrm{O}_{4}$ layer and in internal oxides in the alloy matrix. The $\mathrm{Ti}$ oxides outside the $\mathrm{MnCr}_{2} \mathrm{O}_{4}$ layer correspond with $\mathrm{TiO}_{2}$ in Fig. 3. Internal oxides formed in Inconel 617 also contain some $\mathrm{Ti}$.

In contrast to $\mathrm{Ti}$ and $\mathrm{Mn}$, no $\mathrm{Al}$ was present in the
$\mathrm{Cr}_{2} \mathrm{O}_{3}$ scale. Al forms only internal oxides in the alloy matrix below the $\mathrm{Cr}_{2} \mathrm{O}_{3}$ scale.

Photograph 6 shows characteristic X-ray images of the cross section through the nodular oxide on Inconel 617 corroded for $3000 \mathrm{~h}$. The outer region consisting of columnar oxide grains is rich in $\mathrm{Ni}$ with some Co, and corresponds to $\mathrm{NiO}$ in Fig. 3. The inner region is $\mathrm{Cr}$ internal oxides containing some Co, $\mathrm{Mn}, \mathrm{Mo}$ and Fe.

\section{Gr Depletion Zone}

Figure 4 shows the depth of $\mathrm{Cr}$ depleted zone of the alloys, as a function of exposure time in $\log -\log$ scale. The depth is defined as the depth from the interface of $\mathrm{Cr}_{2} \mathrm{O}_{3}$ scale and alloy matrix to the point where Cr concentration reverts to the bulk value. ${ }^{18)}$ By a line analysis of $\mathrm{Cr}-\mathrm{K} \alpha$ characteristic X-ray intensity using an electron probe microanalyzer, the depth is 

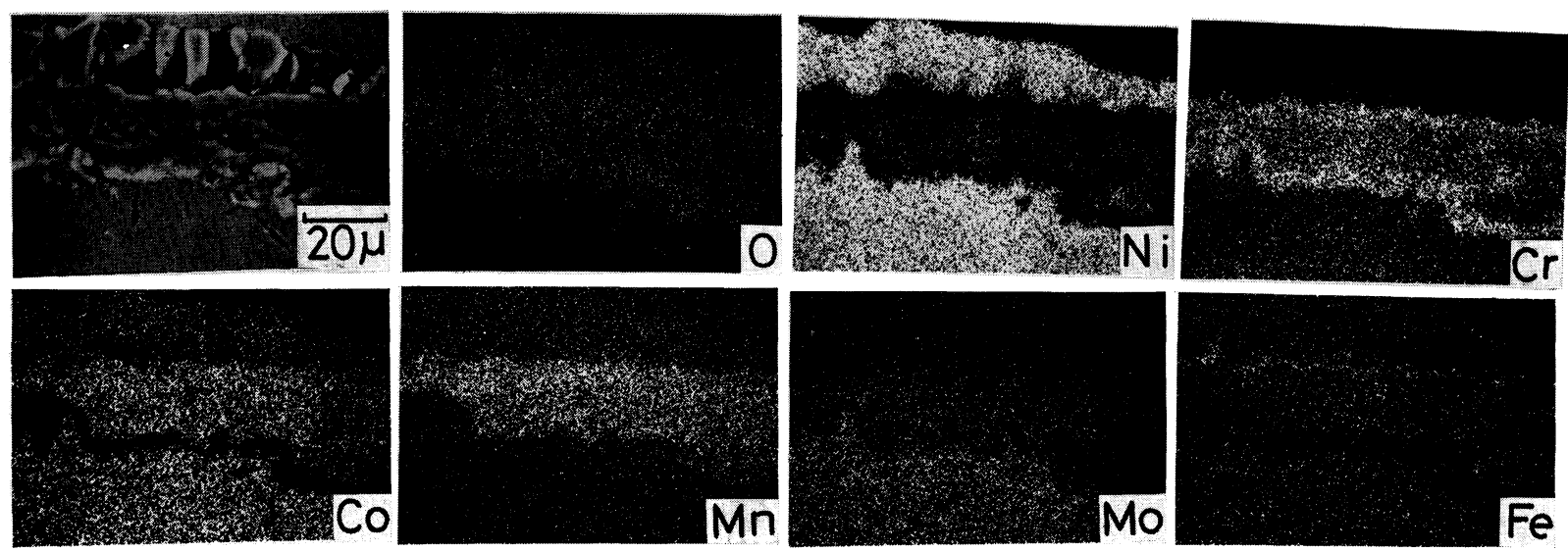

Photo. 6. Characteristic X-ray images of the cross section through nodular oxide formed on Inconel 617 corroded for $3000 \mathrm{~h}$ in steam at $800{ }^{\circ} \mathrm{C}$ and $40 \mathrm{~atm}$. Upper left-hand corner is secondary electron micrograph.

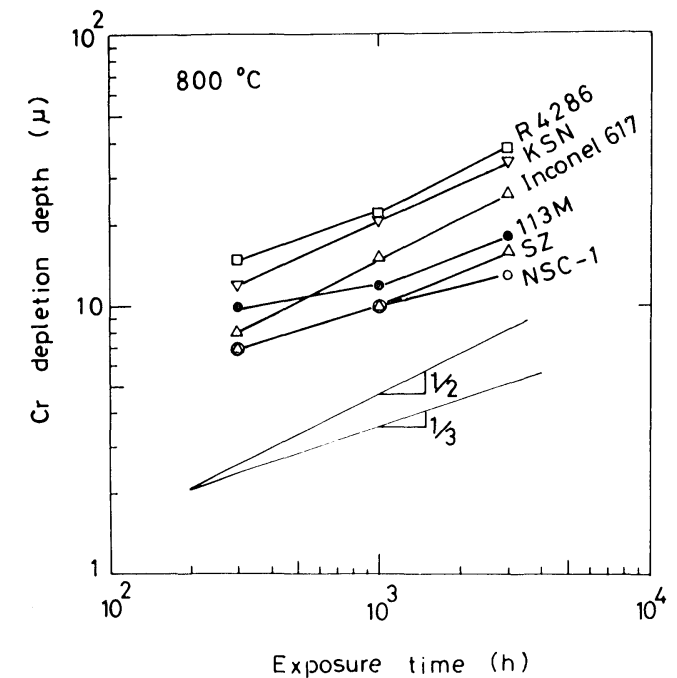

Fig. 4. Depth of $\mathrm{Cr}$ depleted zone beneath the $\mathrm{Cr}_{2} \mathrm{O}_{3}$ scale of the alloys in steam at $800{ }^{\circ} \mathrm{C}$ and $40 \mathrm{~atm}$, as a function of exposure time.

measured at six positions on the cross section of the alloys and an average of the six measured values is taken.

Comparing the depth of $\mathrm{Cr}$ depleted zone in Fig. 4 with the weight gain in Fig. 2, it is evident that the alloys with larger weight gains have also larger $\mathrm{Cr}$ depletion. For example, R4286 has the largest weight gain and the largest depth of Cr depleted zone of the alloys. The correlation between the weight gain and the depth of $\mathrm{Cr}$ depleted zone is because the main component of the surface oxide scale is $\mathrm{Cr}_{2} \mathrm{O}_{3}$ in each alloy. The difference in the depth of $\mathrm{Cr}$ depleted zone is found to be not larger.

The time exponent of the $\mathrm{Cr}$ depletion curves in Fig. 4 is about $1 / 2$, corresponding to a parabolic rate law, for R4286, KSN and Inconel 617, and about $1 / 3$, corresponding to a cubic rate law, for $113 \mathrm{M}$, SZ and NSC-1.

\section{Internal Oxidation}

As shown in Photos. 3 and 5, a large number of root-like internal oxides are formed in the matrix of R4286 and Inconel 617. Figure 5 shows parabolic

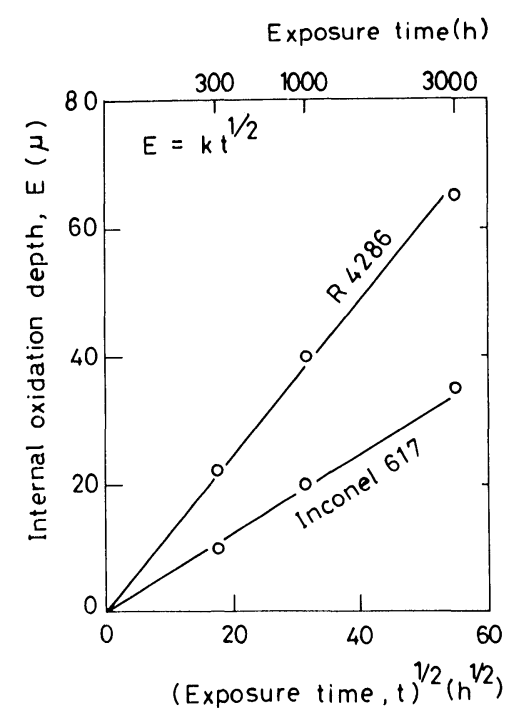

Fig. 5. Parabolic plot of internal oxidation depth of the alloys in steam at $800{ }^{\circ} \mathrm{C}$ and $40 \mathrm{~atm}$.

plots of the internal oxidation depth for the two alloys. The linear relationship suggests that the internal oxidation process is described by a parabolic rate law with the rate constant of 1.23 for R4286 and 0.62 $\left(\mu \mathrm{m} / \mathrm{h}^{1 / 2}\right)$ for Inconel 617.

As shown in Photo. 5, the internal oxides formed in the two alloys are Al- and Ti-oxides. In particular, the internal oxides are rich in $\mathrm{Al}$ rather than $\mathrm{Ti}$ near the tip. On the other hand, no internal oxide was found in NSG-1 and $113 \mathrm{M}$ which contain about $0.5 \% \mathrm{Ti}$ similar to Inconel 617 but no or only a trace of $\mathrm{Al}$. These suggest that $\mathrm{Al}$ is required for the formation of the internal oxides.

Figure 6 shows the parabolic rate constants for the internal oxidation in R4286 and Inconel 617, as a function of atomic concentration of $\mathrm{Al}$ in the bulk which is evaluated from the weight concentrations in Table 1. The rate constant increases linearly with the $\mathrm{Al}$ concentration in the bulk.

\section{Carbon Concentration}

Figure 7 shows carbon concentration of the alloys as a function of exposure time. No change in carbon 


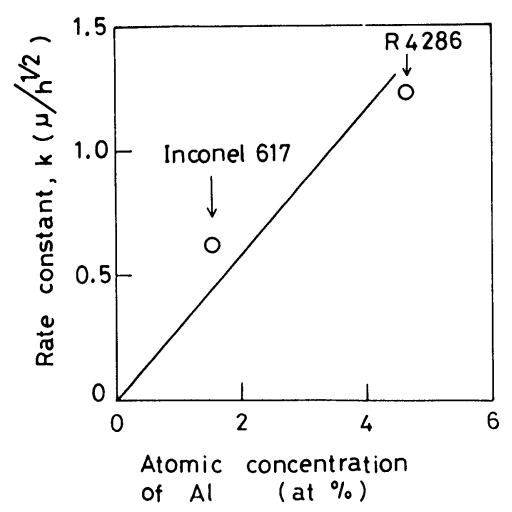

Fig. 6. Parabolic rate constant for internal oxidation vs. atomic concentration of $\mathrm{Al}$ in the bulk of the alloys.

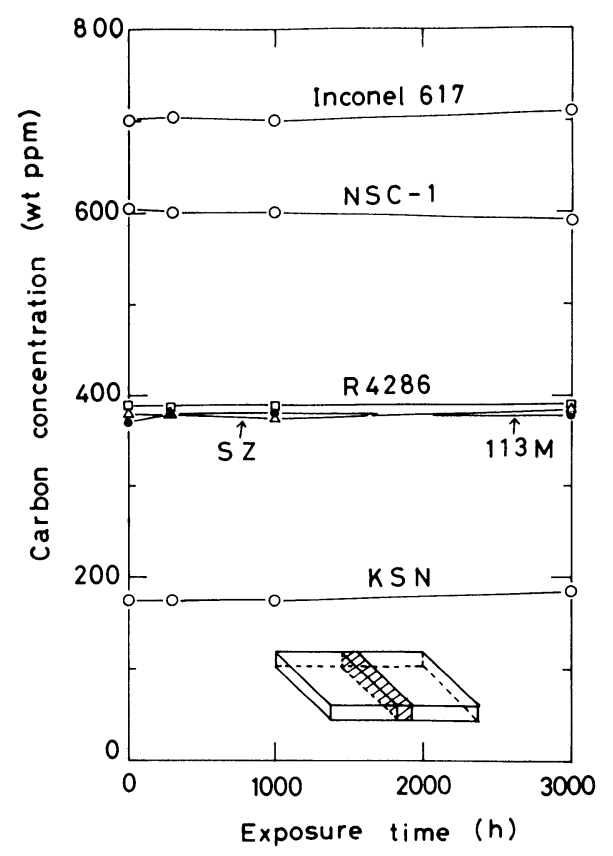

Fig. 7. Carbon concentration of the alloys as a function of exposure time. For carbon analysis, the hatched part shown in the figure was cut by using watercooled fine cutter.

concentration occurs in all the alloys. The gas potential of the steam used in this experiment is characterized by a partial pressure of oxygen of $10^{-5}$ atm and carbon activity of zero, as will be described later. Therefore, the steam is regarded thermodynamically as oxidizing and hence as a decarburizing environment. Nevertheless, no decarburization occurred in the alloys. This is in contrast to the cases in impure helium environments, where considerable decarburization or carburization occurs depending on the gas potential. ${ }^{9-12)}$ No decarburization in the steam is attributable to that the surface oxide scale is protective and the carbon transfer from the alloy matrix to the steam is prevented by the scale.

\section{Discussion}

\section{Oxidation Behavior of $\mathrm{Cr}$ and $\mathrm{Mn}$}

The partial pressure of oxygen $P_{\mathrm{O}_{2}}$ in the steam used in this experiment is evaluated to be $1 \times 10^{-5}$ $\mathrm{atm}^{15)}$ which is produced both by the decomposition of $\mathrm{H}_{2} \mathrm{O}$ molecules, mainly, and by the dissolved oxygen in the water supplied to the autoclave. In the steam of $P_{\mathrm{O}_{2}}=1 \times 10^{-5} \mathrm{~atm}$ at $800^{\circ} \mathrm{C}$, each element in the alloys can react with oxygen to form thermodynamically stable oxides such as $\mathrm{NiO}$ and $\mathrm{Cr}_{2} \mathrm{O}_{3}$.

Selective oxidation of the reactive elements, $\mathrm{Cr}$, $\mathrm{Ti}, \mathrm{Mn}$ and $\mathrm{Al}$, was found to occur on the alloys except Inconel 617, although even $\mathrm{NiO}$ is stable thermodynamically in the steam. The surface oxide scale consisted of $\mathrm{Cr}_{2} \mathrm{O}_{3}$, containing some Ti in solution, and $\mathrm{MnCr}_{2} \mathrm{O}_{4}$. The major component of the scale was $\mathrm{Cr}_{2} \mathrm{O}_{3}$. The rate of formation of the $\mathrm{Cr}$ depleted zone resulting from the formation of $\mathrm{Cr}_{2} \mathrm{O}_{3}$ rich scale was divided into two types; a parabolic rate for R4286, KSN and Inconel 617, and a cubic rate for $113 \mathrm{M}, \mathrm{SZ}$ and NSG-1.

The formation of the $\mathrm{Cr}$ depleted zone is considered to depend on the thickness of the $\mathrm{MnCr}_{2} \mathrm{O}_{4}$ layer formed outside the $\mathrm{Cr}_{2} \mathrm{O}_{3}$ scale. The growth rate of pure $\mathrm{Cr}_{2} \mathrm{O}_{3}$ scale has been shown to be parabolic by many authors. The parabolic growth of the $\mathrm{Cr}_{2} \mathrm{O}_{3}$ scale is suppressed by the formation of the thick $\mathrm{MnCr}_{2} \mathrm{O}_{4}$ layer outside the $\mathrm{Cr}_{2} \mathrm{O}_{3}$ scale and the formation of the resulting $\mathrm{Cr}$ depleted zone follows a cubic rate law. The thick layer of $\mathrm{MnCr}_{2} \mathrm{O}_{4}$ was found to form on NSC-1 and SZ which showed a cubic rate increase for the $\mathrm{Cr}$ depleted zone, while the very thin layer of $\mathrm{MnCr}_{2} \mathrm{O}_{4}$ was found on $\mathrm{KSN}$ and Inconel 617 which exhibited a parabolic rate growth of the $\mathrm{Cr}$ depleted zone.

Shindo and Kondo ${ }^{18)}$ reported that the Mn addition improved the oxidation resistance of Hastelloy-X nearly proportionally to the increase of $\mathrm{Mn}$ content in the range up to $1.32 \mathrm{wt} \%$. They showed that with increasing $\mathrm{Mn}$ content, the thickness of the $\mathrm{MnCr}_{2} \mathrm{O}_{4}$ layer outside the $\mathrm{Cr}_{2} \mathrm{O}_{3}$ scale increased and the $\mathrm{Cr}$ depletion behind the scale decreased.

Nodular oxides containing $\mathrm{NiO}$ were formed on Inconel 617 after $1000 \mathrm{~h}$. As shown in a previous report, ${ }^{15)}$ the formation of the nodular oxides is due to mechanical breakdown of the protective $\mathrm{Cr}_{2} \mathrm{O}_{3}$ rich scale. The nodular oxide formation was also reported on Inconel 600 in high-temperature steam. ${ }^{15}$ )

\section{Oxidation Behavior of $\mathrm{Al}$ and $\mathrm{Ti}$}

As shown in Photo. 5, Al formed only internal oxides below the $\mathrm{Cr}_{2} \mathrm{O}_{3}$-rich scale, while Ti formed not only internal oxides but also oxides in the $\mathrm{Cr}_{2} \mathrm{O}_{3^{-}}$ rich scale and the granular oxides of $\mathrm{TiO}_{2}$ outside the $\mathrm{MnCr}_{2} \mathrm{O}_{4}$ layer in $\mathrm{R} 4286$. Thus, $\mathrm{Ti}$ oxides were formed both externally and internally, while $\mathrm{Al}$ oxides were only internal oxides.

The difference of the oxidation behavior of $\mathrm{Al}$ and Ti can be explained by a difference of diffusion rates of Al- and Ti-ions in the oxides. The extrapolation of Arrhenius relationship of diffusion coefficients measured at high temperatures ${ }^{19,20)}$ gives the diffusion coefficients of $1.7 \times 10^{-22} \mathrm{~cm}^{2} / \mathrm{sec}$ for $\mathrm{Al}$ ions in $\mathrm{Al}_{2} \mathrm{O}_{3}$ and $1.2 \times 10^{-15} \mathrm{~cm}^{2} / \mathrm{sec}$ for $\mathrm{Ti}$ ions in $\mathrm{TiO}_{2}$ at $800^{\circ} \mathrm{C}$. The mean diffusion distance is $\sqrt{ } D t$, where 
$D$ is the diffusion coefficient and $t$ the time. This is only $10^{-2} \mu \mathrm{m}$ for $\mathrm{Al}$ ions even for $t=1 \times 10^{3} \mathrm{~h}$, suggesting that $\mathrm{Al}$ ions are virtually immobile in the oxide. Therefore, the growth of $\mathrm{Al}_{2} \mathrm{O}_{3}$ proceeds by an inward diffusion of oxygen and not by an outward diffusion of $\mathrm{Al}$ ions. On the other hand, the mean diffusion distance of $\mathrm{Ti}$ ions is as large as $1 \mu \mathrm{m}$ after only $1 \mathrm{~h}$. This suggests that $\mathrm{Ti}$ ions have enough mobility to migrate through the $\mathrm{Cr}_{2} \mathrm{O}_{3}$-rich scale of about $10 \mu \mathrm{m}$ thickness and can form Ti oxides outside the oxide scale.

No formation of the $\mathrm{TiO}_{2}$ granules was observed on the alloys except R4286. NSC-1, 113M and Inconel 617 have about $0.5 \mathrm{wt} \% \mathrm{Ti}$ in the bulk as shown in Table 1 , and $\mathrm{Ti}$ oxides were in the $\mathrm{Cr}_{2} \mathrm{O}_{3}$-rich scale in the form of in-solution, and internal $\mathrm{Ti}$ oxides were present only in Inconel 617. Ti content of $0.5 \mathrm{wt} \%$ in the bulk is considered to be too small to form $\mathrm{TiO}_{2}$ granules such as those on R4286.

\section{Spalling of Surface Oxide Scale}

The surface oxide scale formed on SZ and KSN spalled during cooling of the specimens after the corrosion test. The spalling is an important factor for corrosion resistance, because it may cause the scale plugging in stainless steel superheater tubes in electric power plants. ${ }^{3)}$ In the following we discuss a correlation between the occurrence of spalling and alloy compositions.

As shown in Photo. 3, the surface oxide scale on SZ and KSN was separated from the alloy matrix and showed a dome-like shape. The cause of this shape is considered as follows. Compressive stress is produced in the surface oxide scale during cooling, because the alloy matrix has a large thermal expansion coefficient than the oxide scale and hence contracts in volume more than the oxide. Therefore, if the adhesion between the surface scale and the matrix is poor and the compressive stress in the scale is not relaxed, the separation of the surface scale and then the bending of the scale into the dome-like shape will result. The successive separation causes the eventual spalling of the surface oxide scale.

The morphology of the surface oxide scale depends whether compressive stress produced in the scale is relaxed or not. The relaxation is considered to be difficult for the scale on SZ and KSN and easy for that on NSG-1 and $113 \mathrm{M}$, because the scale consists of densely packed oxide grains on SZ and KSN and of porous oxides on NSG-1 and 113M as shown in Photo. 2. On the other hand, no spalling of the scale occurs on R4286 and Inconel 617, in spite of the densely packed oxide scale similar to that on SZ and KSN. For R4286 and Inconel 617, the surface oxide scale is fastened by key-on effect of root-like internal oxides. The addition of rare earth elements such as $\mathrm{Y}$ and $\mathrm{Ce}$ in heat resisting alloys had been known to improve the adhesion of surface oxide scale by key-on effect. ${ }^{21)}$

Besides the internal oxides, Ti oxides are important for the improvement of the adhesion of the surface oxide scale. The alloys except SZ and KSN contain some $\mathrm{Ti}$ in the bulk as in Table 1 and the enrichment of $\mathrm{Ti}$ oxides was found close to the interface between the $\mathrm{Cr}_{2} \mathrm{O}_{3}$ scale and the alloy matrix. The enrichment of $\mathrm{Ti}$ oxides at the interface improves the adhesion of the surface oxide scale by an effect similar to key-on effect.

SZ and KSN which show the spalling of the surface oxide scale are characterized by the absence of $\mathrm{Al}$ and $\mathrm{Ti}$ which are reactive more than Cr. Elements other than $\mathrm{Al}$ and $\mathrm{Ti}$ and reactive more than $\mathrm{Cr}$ also form stable oxides below the $\mathrm{Cr}_{2} \mathrm{O}_{3}$ scale and improve the adhesion of the $\mathrm{Cr}_{2} \mathrm{O}_{3}$ scale. However, the addition of reactive elements should be controlled, because needless internal oxides may accelerate the initiation and the propagation of cracks. ${ }^{22}$ )

\section{Conclusion}

The corrosion behavior of five nickel base heat resisting alloys, developed newly for the metallic components of the nuclear steelmaking system, and Inconel 617 is investigated in steam at $800{ }^{\circ} \mathrm{C}$ and 40 atm. The main results are;

(1) The surface oxide scale consists of $\mathrm{Cr}_{2} \mathrm{O}_{3}$ and $\mathrm{MnCr}_{2} \mathrm{O}_{4}$ on the alloys except Inconel 617 . The main component is $\mathrm{Cr}_{2} \mathrm{O}_{3}$. Root-like internal oxides consisting of $\mathrm{Al}$ and $\mathrm{Ti}$ oxides are formed in the matrix of R4286 and Inconel 617. On Inconel 617 , a large number of nodular oxides containing $\mathrm{NiO}$ forms in addition to $\mathrm{Cr}_{2} \mathrm{O}_{3}$ and $\mathrm{MnCr}_{2} \mathrm{O}_{4}$ after $1000 \mathrm{~h}$. R4286 contains the highest concentration of $\mathrm{Ti}, 2.4 \%$, of the alloys examined. In the alloy a large number of $\mathrm{TiO}_{2}$ granules forms outside the $\mathrm{MnCr}_{2} \mathrm{O}_{4}$ layer.

(2) The rate of the formation of the $\mathrm{Cr}$ depleted zone resulting from the formation of the $\mathrm{Cr}_{2} \mathrm{O}_{3}$-rich scale is described by two types of relations; a parabolic rate relation for $\mathrm{R} 4286, \mathrm{KSN}$ and Inconel 617 , and a cubic rate relation for NSG-1, SZ and 113M. The parabolic growth of the $\mathrm{Cr}_{2} \mathrm{O}_{3}$ scale and the resulting Gr depletion are considered to be suppressed by the formation of the thick layer of $\mathrm{MnCr}_{2} \mathrm{O}_{4}$ outside the $\mathrm{Cr}_{2} \mathrm{O}_{3}$ scale.

(3) The kinetics of internal oxidation is described by a parabolic rate law. The parabolic rate constant increases linearly with the Al content in the bulk.

(4) The surface oxide scale on $\mathrm{SZ}$ and KSN spalled during cooling of the specimens after the corrosion test. The alloys except SZ and KSN contain some $\mathrm{Al}$ and $\mathrm{Ti}$ which are reactive more than $\mathrm{Cr}$. These reactive elements form internal oxides below the $\mathrm{Cr}_{2} \mathrm{O}_{3}$ scale and oxides at the $\mathrm{Cr}_{2} \mathrm{O}_{3} /$ alloy interface, improving the adhesion of the surface oxide scale.

(5) No decarburization occurs in the alloys. It is considered that the surface oxide scale is protective and the carbon transfer from the alloy matrix to the steam is prevented by the scale.

\section{Acknowledgements}

The authors wish to express their thanks to Nippon Steel Corp. for supplying the alloy NSC-1, Sumitomo Metal Industries, Ltd. for SZ, Kobe Steel, Ltd. for 
KSN, Hitachi Metals Ltd. for 113M and R4286, and Ishikawajima-Harima Heavy Industries Co., Ltd. for Inconel 617. The authors are indebted to the members of the Engineering Research Association of Nuclear Steelmaking (ERANS) for their valuable comments. The authors are also very grateful to Dr. T. Hirano and Dr. T. Noda at National Research Institute for Metals (NRIM) for helpful discussion and to Dr. T. Suzuki at NRIM for carbon analysis.

\section{REFERENCES}

1) K. Shimokawa: Trans. ISIJ, 19 (1979), 291.

2) R. Tanaka and T. Kondo: Nucl. Technol., 66 (1984), 75.

3) D. Moroishi: Corrosion Engineering (Boshoku Gijutsu), 25 (1976), 97.

4) Y. Hosoi, M. Sakakibara, N. Shinoda, Y. Tsuchida, S. Sekino, S. Aoki and N. Masui: Tetsu-to-Hagané, 65 (1979), 1004.

5) T. Yukitoshi, Y. Sawaragi and K. Yoshikawa: Tetsu-toHagané, 65 (1979), 994.

6) S. Ohta, K. Aota and T. Motoda: Tetsu-to-Hagané, 65 (1979), 1031.

7) R. Watanabe and Y. Chiba: Tetsu-to-Hagané, 63 (1977), 118.

8) R. Watanabe and T. Kuno: Tetsu-to-Hagané, 61 (1975), 2274 .

9) F. Abe, Y. Sakai, T. Tanabe, H. Araki, T. Suzuki, H. Yoshida and R. Watanabe: Tetsu-to-Hagané, 68 (1982),
2531.

10) T. Tanabe, T. Shikama, Y. Sakai, M. Fujitsuka, H. Araki, H. Yoshida and R. Watanabe: Tetsu-to-Hagané, 69 (1983), 2045.

11) T. Tanabe, T. Shikama, Y. Sakai, M. Fujitsuka, H. Araki, H. Yoshida and R. Watanabe: Tetsu-to-Hagané, 69 (1983), 2052.

12) T. Tanabe, Y. Sakai, T. Shikama, M. Fujitsuka, H. Yoshida and R. Watanabe: Nucl. Technol., 66 (1984), 260.

13) K. Furuya, T. Hirano, T. Kainuma and H. Yoshida: Proc. JIMS-3, High Temperature Corrosion, Trans. JIM Suppl., (1983), 547.

14) N. Kishimoto, T. Tanabe, H. Araki, H. Yoshida and R. Watanabe: Nucl. Technol., 66 (1984), 578.

15) F. Abe, H. Araki, H. Yoshida, M. Okada and R. Watanabe: Corros. Sci., 21 (1981), 819.

16) M. Kikuchi, R. Tanaka, M. Kajiwara, Y. Kadoya and S. Takeda: Report of the 123rd Committee on Heat-resisting Metals and Alloys, Japan Society for the Promotion of Science, 22 (1981), 31.

17) F. Abe and T. Tanabe: Proc. Japan-U.S. Seminar on Superalloys, (1985), (in press).

18) M. Shindo and T. Kondo: Telsu-to-Hagané, 68 (1982), 1628.

19) A. E. Paladino and W. D. Kingery: J. Chem. Phys., 37 (1962), 957.

20) D. L. Venkatsu and L. E. Poteat: Mat. Sci. Eng., 5 (1969/ 70), 258.

21) Y. Saito: Tetsu-to-Hagané, 65 (1979), 747.

22) S. Ohta: J. Soc. Mat. Sci. Japan, 23 (1974), 174. 